\title{
Organic Catalysis
}

\author{
By E. Emmet Reid
}

Johns Hopkins UnIVERSITy, BaLtimore, MARYlaNd

$\mathbf{T}$ HE PAST year has seen much activity in the study of the mechanism of catalysis and a more exact study of the influence of the precise method of preparation of a catalyst on its activities, both qualitatively and quantitatively. The most striking contributions to the literature are briefly summarized in the following paragraphs.

The mechanism of catalysis has been studied by Langmuir. ${ }^{1} \quad$ Taylor and Burns ${ }^{2}$ lay a foundation for reasoning and calcu-. lating by measuring the adsorption of hydrogen, carbon monoxide, carbon dioxide, and ethylene by nickel, cobalt, iron, platinum, and palladium. They find that adsorption is specific and that saturation is reached at low pressures. Preparations of the metals which are good absorbers are good catalysts.

Palmer and Palmer ${ }^{3}$ make an intensive study of the hydrogenation of ethylene and explain all their results in terms of the absorption of hydrogen or ethylene on the surface of the nickel. At first the metal is covered with hydrogen and the reaction is slow. Some of this is driven off by the heat of the reaction and ethylene con-

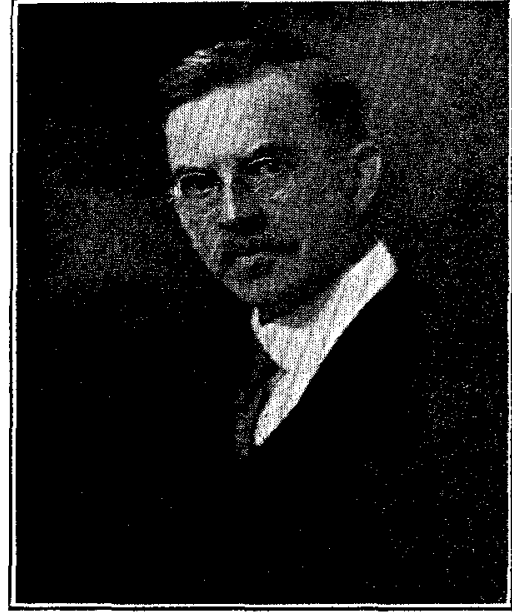

E. EMMETT RETD pressures of the hydrogen from ethyl and isopropyl alcohols between $105^{\circ}$ and $275^{\circ}$ over a copper catalyst.

Matignon ${ }^{8}$ and Herzfeld consider the formation of intermediate compounds from the standpoint of thermodynamics.

Dhar and Mittra ${ }^{9}$ find that the oxidation of a more oxidizable substance is slowed down in the presence of the substance in which it induces oxidation. The second substance may be considered a negative catalyst. The explanation may be found in the formation of complexes.

Burrows ${ }^{10}$ finds that the addition of sucrose, which is itself hydrolyzed, slightly accelerates the hydrolysis of methyl acetate by hydrochloric acid.

Sherman and co-workers ${ }^{11}$ measure the influence of amino acids, copper salts, etc., on the activity of amylases.

Coffey ${ }^{12}$ upsets tradition by showing that, under the influence of driers, oils take up only 0.6 as much oxygen as without.

Taylor and Lewis ${ }^{13}$ study the absorption spectra of triethyl sulfonium bromide in eight solvents in an attempt to find a connection between reactions and light denses on a part of the surface. This is the condition of maximum efficiency and the reaction slows up when too much ethylene chokes up the surface.

Ridea ${ }^{4}$ can find no period of induction except when oxygen is present. He adopts Langmuir's view that the metal is covered with a film of hydrogen and ethylene one molecule deep and that the reaction is between the ethylene and hydrogen molecules that find themselves adjacent in this film.

Maxted $^{5}$ makes a quantitative study of the influence of poisons, lead, mercury, sulfur, and zinc, on the occlusion of hydrogen by palladium and on the catalytic power of platinum and palladium. The rate at which hydrogen is taken up is affected far more than the amount, two weeks being required for saturation with 19 per cent of lead on the palladium. With 17 per cent of lead the amount of hydrogen absorbed is reduced only 50 per cent while the rate of hydrogenation is decreased 98 per cent, which indicates that the catalytic action is confined to the surface. To cut the catalytic activity of platinum in half requires 10 per cent mercury or sulfur and only 4 per cent arsenic or zine.

Armstrong and Hilditch ${ }^{6}$ study the relation between the pressure of the hydrogen and the rate of hydrogenation. It appears that $\mathrm{H}_{2}$ rather than $\mathrm{H}$ is the reactant, the rate being directly proportional to the pressure, provided at least 0.1 per cent nickel is present. With 0.01 per cent, the rate is too low, which seems to show that a part of the metal is combined with the ethylene groups.

Rideal ${ }^{7}$ makes a valuable addition to our scanty quantitative data on hydrogenation by determining the dissociation

1 Trans. Faraday Soc., adv. proof 1921; C. A., 16 (1922), 864.

2.J. Am. Chem. Soc., 43 (1921), 1273.

3 Proc. Roy. Soc. (London), 99 A (1921), 402.

4 J. Chem. Soc. 121 (1922), 309.

s Ibid., 119 (1921), 225, 1280.

6 Proc. Roy, Soc. (London), 100A (1921), 240.

7 lbid., 99 A (1921), 153. absorption. Most of the absorption bands were in the calculated positions,

Baly, Heilbron, and Barker ${ }^{14}$ effect the photosynthesis of formaldehyde from carbon dioxide in water illuminated by light of short wave length, $\lambda=200 \mu \mu$. The formaldehyde passes into reducing sugars in light of $\lambda=290 \mu \mu$. In the presence of certain colored substances, the photosynthesis takes place under the influence of visible light:

Schwarz and Friedrich ${ }^{15}$ find that Röntgen rays poison a platinum catalyst.

Rosenmund and Zetzsche ${ }^{16}$ have made an extensive study of stopping reactions at the desired place. The following reactions oecur by catalytic hydrogenation: benzoyl chloride $\longrightarrow$ benzaldehyde $\longrightarrow$ benzyl alcohol $\longrightarrow$ toluene. By adding a trace of sulfurized quinoline, 88 per cent aldehyde can be obtained.

Adkins and Krause ${ }^{17}$ conclude that the method of preparation of a catalyst is of equal, if not greater, importance than the particular metallic element present.

Willstätter and Waldschmidt-Leitz ${ }^{18}$ claim that hydrogenation cannot be effected with platinum or palladium free from oxygen, and suggest that catalytic poisons remove this all-important oxygen. Their experiments appear exact and convincing. H. S. Taylor explains their results by assuming that a catalyst may so cover itself up with hydrogen that the

8. Chim. et industrie, 6 (1921), 7; Z. phys, Chem., 98 (1921), 161.

${ }^{9}$ Chem. News, 123 (1921), 313.

${ }^{10} \mathrm{~J}$. Chem. Soc., 119 (1921), 1798.

${ }_{11} \mathrm{~J}$. Am. Chem. Soc., 43 (1921), 2454, 2461, 2469.

$12 \mathrm{~J}$. Chem. Soc., 121 (1922), 17

18 Ibid., 121 (1921), 665.

${ }_{14}$ Ibid., 119 (1921), 1025.

15 Ber., 55 (1922), 1040 .

18 Ibid., 54 (1921), 425, 638, 1092, 2033, 2038;55 (1922), 609; Abel, Ibid., 54 (1921), 1407; 55 (1922), 322 .

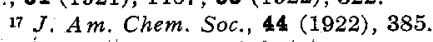

18 Ber., 54 (1921), 113. 